\title{
The Brazilian Business and Growth Cycles*
}

\author{
Marcelle Chauvet**
}

Summary: 1. Introduction; 2. The model; 3. Empirical results; 4. Out-of-sample forecasting; 5 . Conclusions.

Key words: business cycle; growth cycle; Markov switching; nonparametric rules.

JEL codes: C32; C50 and E32.

This paper uses several procedures to date and analyze the Brazilian business and growth cycles. In particular, a Markov switching model is fitted to quarterly and annual real production data. The smoothed probabilities of the Markov states are used as predictive rules to define different phases of cyclical fluctuations of real Brazilian production. The results are compared with different nonparametric rules. All methods implemented yield similar dating and reveal asymmetries across the different states of the Brazilian business and growth cycles, in which slowdowns and recessions are short and abrupt, while high growth phases and expansions are longer and less steep. The resulting dating of the Brazilian economic cycles can be used as a reference point for construction and evaluation of the predictive performance of coincident, leading, or lagging indicators of economic activity. In addition, the filtered probabilities obtained from the Markov switching model allow early recognition of the transition to a new business cycle phase, which can be used, for example, for evaluation of the adequate strength and timing of countercyclical policies, for reassessment of projected sales or profits by businesses and investors, or for monitoring of inflation pressures.

Este artigo utiliza vários métodos para datar e analisar ciclos de negócios e de crescimento no Brasil. Em particular, um modelo de mudanças de Markov é aplicado a dados de produção trimestrais e anuais. As probabilidades suavizadas dos estados markovianos são utilizadas como regras de previsão para definir as diferentes fases de flutuações cíclicas na produção real brasileira. Os resultados são comparados com diferentes regras não-paramétricas. Todos os métodos implementados geram uma cronologia similar e revelam assimetrias nas diferentes fases dos ciclos de negócio e de crescimento do Brasil, nos quais os estados de baixo crescimento e recessão são de curta duração e mais abruptos, enquanto os estados de crescimento acelerado e expansão são mais longos e graduais. As datas dos ciclos obtidas podem ser utilizadas como pontos de referência para a construção e avaliação do poder de previsão de indicadores coincidentes, antecedentes e defasados da atividade econômica. Além disso, as

\footnotetext{
${ }^{*}$ This paper was received in Nov. 2000 and approved in Sept. 2001.

** Department of Economics/University of California (Riverside, USA). The author benefited from comments and suggestions from two anonymous referees, and from seminar participants at FGV and at UFRJ's Statistics Department.
} 
probabilidades filtradas obtidas do modelo de mudança de estado de Markov permitem um reconhecimento tempestivo da transição da economia para uma nova fase econômica, o que pode ser utilizado, por exemplo, na avaliação da medida adequada de políticas contracíclicas, na reavaliação de vendas e lucros projetados por firmas e investidores, ou no monitoramento de pressões inflacionárias.

\section{Introduction}

Market economies undergo recurrent fluctuations in aggregate activity. People and firms affected by changes in sales, profits, credit, or employment are very concerned about these swings in the economy. On the other hand, policymakers are also attentive to the differential effects of certain policies, depending on the stage of the business cycle. For example, an increase in interest rates may have a different impact depending on whether business is slow or the economy is booming. Hence, there is a great interest in understanding, measuring, monitoring, and forecasting business cycles.

One of the pioneering studies on business cycles is the work of the National Bureau of Economic Analysis (NBER), founded in the 1920s. The NBER's methodology for empirical analysis of business cycle is summarized in the seminal work of Mitchell (1927) and Burns and Mitchell (1946), which established the following definition: "Business cycles are a type of fluctuation found in the aggregate economic activity of nations that organize their work mainly in business enterprises: a cycle consists of expansions occurring at about the same time in many economic activities, followed by similarly general recessions, contractions and revivals that merge into the expansion phase of the next cycle; this sequence of changes is recurrent but not periodic. In duration business cycles vary from more than a year to ten or twelve years; they are not divisible into shorter cycles of similar character with amplitudes approximating their own."

Burns and Mitchell examined the US business cycle based on this definition, and then classified macroeconomic variables as leading, coincident, or lagging according to their conformity to this reference cycle. Based on this comprehensive empirical study, the US Department of Commerce started compiling combinations of these variables as composite indexes in the $1960 \mathrm{~s},{ }^{1}$

\footnotetext{
${ }^{1}$ The task of computing and revising the composite indicators was passed to the Conference Board in 1995, which is a private non-profit organization.
} 
which have since then been used to monitor and forecast business cycle turning points. ${ }^{2}$ These indicators have become very popular in the US, and have inspired the construction and use of similar ones in several other countries. The private sector and policymakers worldwide use these tools to form expectations about the current and future state of the business cycle.

The primary step in constructing composite indicators is the existence of a business cycle chronology that can be used as a common reference point for analysis. The NBER Business Cycle Dating Committee has been dating the US expansions and recessions for the last 50 years. Decisions about business cycle turning points are reached from a subjective consensus among the members of the committee. The analysis is based on cyclical variation of several variables that move together with business cycles, such as manufacturing and trade sales, personal income, industrial production, and nonagricultural employment, among others. The decision of the committee is generally accepted as the official dating of the US business cycle and it provides economists with a benchmark for analysis of economic activity.

Although careful deliberations are applied to determine turning points, the NBER procedure cannot be used to monitor business cycles. The Business Cycle Committee meets months after a turning point has occurred, and a decision is only released when there is no doubt regarding the dating. This can only be achieved by examining a substantial amount of ex post revised data. Thus, the NBER dating cannot be used in real time. In addition, since the final results are based on subjective discussions rather than on formal models, they cannot be tested by statistical methods.

The NBER techniques to date expansions and recessions and to construct composite indicators have remained a standard for the study of business cycles for many decades. However, the widespread use of economic indicators and awareness of their shortcomings have increased academic interest in this type of analysis. Analytic models that formalize the construction of indicators, and probabilistic frameworks to define and evaluate turning points forecasts have gained popularity. For example, Neftci (1982) proposes a method to spot turning points by calculating the likelihood that the regime has changed. A turning point probability signal is called when the estimated probability

\footnotetext{
${ }^{2}$ In this context, turning points refer to the dates of transition between expansion and recession regimes of business cycles. Peaks are the end of expansions and the beginning of recessions, while troughs are the beginning of expansions and the end of recessions.
} 
reaches a predetermined level of confidence. This approach has been refined by Diebold and Rudebusch (1989) and Hamilton (1989). Diebold and Rudebusch use a Bayesian sequential algorithm to produce ex ante probability forecasts of turning points. Hamilton suggests modeling sudden changes in the behavior of a time series as the outcome of a Markov switching process, which is governed by an endogenous probability rule. In particular, Hamilton fits a Markov switching univariate model to monthly changes in GNP and obtains dates for the US business cycle using the estimated recession probabilities. Chauvet (1998) extends Hamilton's approach using a multivariate Markov switching dynamic factor model. The chronology found from the Markov switching models is highly correlated with the ex post NBER dating. Thus, these formal analytic models can be used to monitor turning points and evaluate forecasts in real time, overcoming the drawbacks of the NBER dating.

This paper uses several different techniques to date turning points of the Brazilian business and growth cycles in the last 100 years. $^{3}$ In particular, a hidden Markov switching model is fitted to quarterly and annual real measures of production, and the endogenous probabilities are used as predictive rules to determine the different phases of cyclical aggregate fluctuations. The results are compared with several non-parametric rules, such as Bry and Boschan's (1971) routine, which is an attempt to formalize the NBER dating rules into a computer program, and the rule of thumb of two consecutive quarters of decrease in GDP. The dating obtained from all these procedures turn out to be very similar. The resulting chronology of the Brazilian business and growth cycles can be used as a reference point for the construction and evaluation of the predictive performance of coincident, leading, or lagging indicators of economic activity. ${ }^{4}$

One of the problems with the $a d$ hoc rules is that they require a substantial amount of ex post data, which implies that turning point dates are not

\footnotetext{
${ }^{3}$ Growth cycles correspond to cyclical variation in the deviations from long-term trend of real production and exhibit two phases: slowdowns and high growth states. Business cycles, on the other hand, correspond to a general downturn or upturn in various sectors of the economy and display two distinct phases: recessions and expansions. Recessions can be interpreted as a more severe slowdown, when the economy grows at negative rates, while expansions are periods of moderate growth. According to Burns and Mitchell's definition, slowdowns precede contractions in the economy, high growth phases correspond to the subsequent revivals, and expansions are phases of normal economic growth.

${ }^{4}$ See, for example, Chauvet (2001), who constructs a monthly composite indicator of Brazilian GDP.
} 
available until a couple of months after the fact. ${ }^{5}$ On the other hand, the model-based approach allows analysis and prediction of business cycles on a timely basis. The filtered probabilities of business cycle phases for date $t$, obtained from the Markov switching model, requires only information up to t. For a historical analysis, however, all methods should be considered for comparison, since the non-parametric rules are not sensitive to changes in the sample.

A timely recognition of an economic contraction and its severity enables a government policy response that could reduce the amplitude and duration of the downturn. In addition, businesses and investors would be able to reassess projected sales or profits based on knowledge of the transition to a new business cycle phase. In fact, several features of the aggregate economy may evolve according to economic cycle stages rather than to calendar time. For example, cyclical changes in inflation can be monitored depending on the state of the economy. A current assessment of the business cycle phase can help identify whether inflationary pressures are arising from tight internal demand or supply markets, which can indicate the adequacy and intensity of policy responses.

The two-state Markov process captures switches and asymmetries across different cycle phases underlying the Brazilian real product. In particular, one state displays a low or negative mean and a shorter average duration, which is associated with economic slowdowns and recessions. The other state exhibits a positive mean and longer average duration, depicting the features of high growth phases and expansions. More specifically, at the annual frequency the Markov switching model depicts different phases of secular growth: during slowdowns the economy grows at an annual rate of $1.15 \%$, while during periods of accelerated growth it averages $7.5 \%$ per year in the last century. At the quarterly frequency, the model identifies periods of expansions when the economy grows at a more moderate annual rate of $5 \%$, and periods of recessions when the economy displays an average negative growth of $6 \%$ per year.

The shape of the Brazilian economic cycles is also examined for the different procedures adopted to date turning points, using measures of duration, amplitude, and cumulative movements within phases, as proposed in Harding and Pagan (2001). Here again, the duration of high growth phases and ex-

\footnotetext{
${ }^{5}$ In fact, a prediction from both rules can not be obtained until at least six months after the turning point has occurred.
} 
pansions is longer than for low growth phases or recessions. In addition, the cumulative losses in output during slowdowns and recessions is much smaller than the cumulative gains during high growth phases and expansions. That is, when the Brazilian economy undergoes prosperous periods the cumulative increase in GDP from the beginning to the end of the phase is very large, which points to the importance of policies that promote growth. These asymmetries regarding duration, amplitude, and deepness across business cycle expansions and recessions are also observed in the OECD countries, as documented, for example, in Chauvet and Yu (2000), Artis and Zhang (1999) or Artis, Kontolemis and Osborn (1997). ${ }^{6}$

The paper is organized as follows. The next section introduces and interprets the model. In the third section, the empirical results are discussed and the resulting Brazilian dating of growth and business cycles is analyzed. The fourth section implements an out-of-sample forecasting exercise to compare the performance of the Markov switching model for changes in GDP with linear alternatives. The fifth section concludes the paper.

\section{The Model}

In order to capture cyclical variation in the Brazilian economy, the log of real GDP, $\widetilde{y}_{t}$, is modeled as the sum of two integrated components: a Markov trend term, $\widetilde{n}_{t}$, and a Gaussian component, $\widetilde{z}_{t}$, as in Hamilton (1989):

$$
\widetilde{y}_{t}=\widetilde{n}_{t}+\widetilde{z}_{t}
$$

The Markov trend is:

$$
\widetilde{n}_{t}=\widetilde{n}_{t-1}+\mu_{s t}
$$

where $s_{t}$ is an unobservable first-order two-state Markov chain and $\mu_{s t}$ is the state-dependent drift term. The drift term $\mu_{s_{t}}$ takes the value of $\mu_{0}$ when the economy is in a low growth phase or in a recession $\left(s_{t}=0\right)$ and $\mu_{1}$ when the economy is in a high growth state or in an expansion $\left(s_{t}=1\right)$. These switches are governed by the transition probability matrix $P_{2}$ with elements $p_{i j}=\operatorname{pr}\left[s_{t}=j \mid s_{t-1}=i\right]$, where $i$ denotes the $i$ th column and $j$ the $j$ th

\footnotetext{
${ }^{6}$ Chauvet and $Y u$ (2000) use a Markov switching dynamic factor model to estimate the business cycles of each of the G-7 countries, and the international business cycles underlying the country-members of the OECD (Organization for Economic Cooperation and Development).
} 
row. Each column of $P_{2}$ sums to one, so that $1_{2}^{\prime} P_{2}=1_{2}^{\prime}$, where $1_{2}$ is a column vector of ones.

Notice that under the assumptions that $P_{2}$ is ergodic and irreducible, the Markov chain is serially correlated, except for the case that each column of the transition matrix is equal to the ergodic probabilities, $\pi$, where $P_{2} \pi=\pi$. In this case, the probability of staying in a state is equal to the probabilities of coming back to this state, given that the economy was in any of the other states. For example, the Markov chain will be serially uncorrelated if $p_{11}=p_{1}$.

The Gaussian component follows a zero mean $\operatorname{ARIMA}(r, 1,0)$ process:

$$
\widetilde{z}_{t}=\widetilde{z}_{t-1}+\phi_{1}\left(\widetilde{z}_{t-1}-\widetilde{z}_{t-2}\right)+\cdots+\phi_{r}\left(\widetilde{z}_{t-r}-\widetilde{z}_{t-r-1}\right)+\varepsilon_{t}
$$

where $\varepsilon_{t} \sim \operatorname{iid} N\left(0, \sigma^{2}\right)$ and $\varepsilon_{t}$ is independent on $n_{t+j}, \forall j$. Taking the first difference of (1), we obtain:

$$
y_{t}=\mu_{s t}+\phi_{1}\left(\widetilde{z}_{t-1}-\widetilde{z}_{t-2}\right)+\cdots+\phi_{r}\left(\widetilde{z}_{t-r}-\widetilde{z}_{t-r-1}\right)+\varepsilon_{t}
$$

for $y_{t}=\widetilde{y}_{t}-\widetilde{y}_{t-1}$. Notice that the first-order assumption of the Markov chain implies that all relevant information for predicting future states is included in the current state, i.e., $\operatorname{pr}\left[s_{t+1} \mid I_{t}, s_{t}, s_{t-1}, \cdots\right]=\operatorname{pr}\left[s_{t+1} \mid s_{t}\right]$. That is, $y_{t}$ depends only on the current and $r$ most recent values of $s_{t}$, on $r$ lags of $y_{t}$, and on a vector of parameters $\theta$ :

$$
\begin{aligned}
& p\left(y_{t} \mid s_{t}, s_{t-1}, \cdots, y_{t-1}, y_{t-2}, \cdots ; \theta\right)= \\
& \quad=p\left(y_{t} \mid s_{t}, s_{t-1}, \cdots, s_{t-r}, y_{t-1}, y_{t-2}, \cdots, y_{t-r} ; \theta\right) \equiv p\left(y_{t} \mid z_{t}, \theta\right)
\end{aligned}
$$

where $z_{t} \equiv\left(s_{t}, s_{t-1}, \cdots, s_{t-r}, y_{t-1}, y_{t-2}, \cdots, y_{t-r}\right)$.

Hamilton (1989) applied this model to the quarterly change in the log of US real GNP from 1952:2 to 1984:4, assuming that the gaussian component follows an $\operatorname{AR}(4)$ process $(r=4)$, and setting $z_{t}=\left(\widetilde{z}_{t}-\widetilde{z}_{t-1}\right)=\widetilde{y}_{t}-\widetilde{y}_{t-1}-$ $\mu_{s t}=y_{t}-\mu_{s t}$. That is,

$$
\begin{aligned}
y_{t} & =\mu_{s t}+\phi_{1}\left(y_{t-1}-\mu_{s t-1}\right)+\phi_{2}\left(y_{t-2}-\mu_{s t-2}\right)+\phi_{3}\left(y_{t-3}-\mu_{s t-3}\right)+ \\
& +\phi_{4}\left(y_{t-4}-\mu_{s t-4}\right)+\varepsilon_{t}
\end{aligned}
$$

The model captures switches between positive and negative growth mean rates of US GNP, and one of its remarkable results is that the estimated filtered and 
smoothed probabilities were closely related to the NBER dating of recessions and expansions.

However, McConnell and Perez-Quiros (2000) have found evidence of a structural break in the volatility of US growth toward stabilization in the first quarter of 1984 - the last year used by Hamilton to estimate the model. ${ }^{7}$ They show that one implication of the break is that the smoothed probabilities miss the 1990 US recession when the model is estimated using more recent years. ${ }^{8}$

There are different ways to handle the problem of structural breaks. McConnell and Perez-Quiros suggest augmenting the model by allowing the residual variance to switch between two regimes, and letting the mean growth rate vary depending on the state of the variance. ${ }^{9}$ The resulting estimated smoothed probabilities of the augmented model capture the 1990/91 recession.

Notice that Hamilton's model decomposes the log of GDP $\left(\widetilde{y}_{t}\right)$ into the sum of two unit roots processes that are not identifiable from each other. In fact, equation (5) sets the two components equal to each other: $\left(\widetilde{z}_{t}-\widetilde{z}_{t-1}\right)=\widetilde{y}_{t}-$ $\widetilde{y}_{t-1}-\mu_{s t}$. Thus, in the presence of a structural break, both terms capture both the business cycle component and the break. ${ }^{10}$ McConnell and Perez-Quiros' model identifies breaks in the variance from breaks in the mean by allowing each to follow different (albeit dependent) Markov processes. Thus, while the Markov chain for the variance captures the break in 1984, the Markov states for the mean capture the business cycle component for the full sample.

As for the US, the Brazilian economy also displays several structural breaks in its dynamics. In particular, the series of stabilization plans and changes in policy regime in the last two decades engendered several breaks in the Brazilian GDP, specially in the early 1990s due to the Collor Plan.

An alternative way of handling the problem of structural breaks proposed here is to model the change in the log of GDP $\left(y_{t}\right)$ as a hidden Markov chain,

\footnotetext{
${ }^{7}$ This result has been further investigated by several authors, such as Kim and Nelson (1999), Koop and Potter (2000), and Chauvet and Potter (2001).

${ }^{8}$ The results from dynamic factor models with Markov regime switching, as estimated in Chauvet (1998) using personal income, sales, employment, and industrial production, are not affected by the use of more recent data that include the structural break.

${ }^{9}$ This amounts to estimating four mean growth rates: low growth under high and low volatility states, and high growth under high and low volatility states.

${ }^{10}$ The smoothed probabilities obtained from a model with switching variance and constant mean captures the break in 1984, while a model with switching mean and constant variance captures the business cycle phases up to the breakpoint (see McConnell and Perez-Quiros, 2000).
} 
setting the autoregressive process in equation $(3)$ equal to zero $(r=0) .{ }^{11}$ In this case, the log of the Brazilian GDP, $\widetilde{y}_{t}$, is a function of an integrated process that follows a Markov chain and of a white noise process. The model is:

$$
\begin{aligned}
\widetilde{y}_{t} & =\widetilde{n}_{t}+\widetilde{z}_{t} \\
\widetilde{n}_{t} & =\widetilde{n}_{t-1}+\mu_{s t} \\
\widetilde{z}_{t} & =\widetilde{z}_{t-1}+\varepsilon_{t}
\end{aligned}
$$

Taking the first difference of (6), we obtain:

$$
y_{t}=\mu_{s t}+\varepsilon_{t}
$$

Notice that maintaining the regularity assumptions of the Markov chain (ergodic, non-periodic, irreducible, homogeneous), the regimes are serially correlated. In fact, the information set of the mean growth rate of Brazilian GDP, $y_{t}$, is now the vector of parameters $\theta=\left(\mu_{0}, \mu_{1}, \sigma, p_{00}, p_{11}\right), z_{t} \equiv\left(s_{t}, y_{t}\right)$, and the serial correlation in $y_{t}$ is captured solely through the serial dependence in the states.

This framework is used here to classify business and growth cycles turning points and to capture potential asymmetric behavior across business cycle phases, the effect of which could be averaged out in a linear analysis of the whole sample data. That is, within this framework, expansions or high growth phases and recessions or slowdowns can display different duration, amplitude, and steepness.

The model is estimated using the filter proposed by Hamilton (1989). The filter calculates the course of the Markov state variable, using only observations on $y_{t}$. It computes recursively one-step-ahead predictions and updating equations of the conditional probabilities of the latent Markov state and, based on them, evaluates the conditional likelihood of the observable variable. The filter evaluates this likelihood function, which can be maximized with respect to the model parameters using an optimization algorithm. The filter yields as output optimal inferences about the probabilities of the latent Markov states, which are used to date growth cycle and business cycle turning points. The

\footnotetext{
${ }^{11}$ Several authors have reported that the log first difference of GDP in the US and other countries is better modeled as a low autoregressive process, including McConnell and Perez-Quiros (2000), Harding and Pagan (2001) or Albert and Chib (1993), among others. In particular, Albert and Chib use Bayesian methods to estimate Hamilton's model and find that the best specification for changes in $G D P$ is an $A R(0)$ process, as the autoregressive coefficients are not statistically significant.
} 
estimation procedure and derivation of the likelihood function are described in Hamilton (1989, 1994).

\section{Empirical Results}

\subsection{Data and specification tests}

The empirical analysis of the Brazilian economic cycles was implemented at both annual and quarterly frequencies. The data were obtained from the Getulio Vargas Foundation (FGV) database. At the annual frequency, the variable used was the real product index from 1900 to 1999. At quarterly frequency, the series used was the real GDP from IBGE (Brazilian Institute for Geography and Statistics), from 1980:01 to 2000:01. ${ }^{12}$ Both series are compiled by IBGE.

Augmented Dickey-Fuller (Dickey \& Fuller, 1979) test for unit roots and Perron (1989) test for unit roots in the presence of structural breaks were implemented and they do not reject the null hypothesis of integration against the alternative of stationarity at any significance level. Thus, both series were modeled as in equation (6), and transformed to achieve stationarity using 100 times their log first difference, as in equation (7).

Tests for the number of states in Markov switching models require nonstandard procedures, since several of the classical assumptions of asymptotic distribution theory do not hold. The number of states is tested using the approach proposed by Garcia (1998), based on Hansen (1993). ${ }^{13}$ The test provides strong evidence for the two-state model.

Before deciding on model (6)-(7), several Markov specifications with different autoregressive processes were estimated for the Brazilian GDP. ${ }^{14}$ The autoregressive parameters are not statistically significant in most cases. For example, for the AR(1) model, the autoregressive parameter is not statistically significant at the $1 \%$ level. Although the log likelihood values of different specifications are close, the resulting probabilities of some models with

\footnotetext{
${ }^{12}$ The first observation available for quarterly data is 1980:01. This series was seasonally adjusted using the $X-11$ method.

${ }^{13}$ Since the transition probabilities are not identified under the null, Hansen (1993) proposes simulation methods to approximate the asymptotic null distribution of a standardized likelihood test, treating the transition probabilities as nuisance parameters. The asymptotic one state null distribution is the supremum over all admissible values in the space of transition probabilities.

${ }^{14}$ The likelihood ratio test was used to choose among alternative specifications of the twostate model.
} 
autoregressive processes capture mostly the outliers in the data. This result is a consequence of the presence of several structural breaks in the Brazilian economy corresponding to the different stabilization plans in the 1980s and 1990s, particularly the Collor Plan in 1990/91, as explained in the previous section. Some of these pulse breaks were very short-lived, resulting in a very small estimated autoregressive process for the period analyzed.

Specification tests are also applied on the assumptions regarding the model residuals. The residuals' sample autocorrelation is close to zero for observations more than one period apart and the autocorrelation functions for the disturbances $\varepsilon_{t}$ are within the limit of two times their asymptotic standard deviation.

\subsection{Results}

The analysis focuses on both business cycle and growth cycle turning points. That is, we are interested in studying not only recessions and expansions, but also periods of low and high growth in output. This analysis may provide a first insight on the interrelation between changes in trends and business cycles in the Brazilian economy.

In order to obtain optimal inferences of growth and business cycle turning points, we need first to define procedures to identify these turns. One of the dating guidelines adopted by the NBER is that recessions correspond to a general downturn in various sectors of the economy for a minimum duration of six months. The idea is to rule out short-term events, such as strikes, tax law changes etc., from a broader downturn. In this paper we adopt this criterion for both recessions and expansions, in order to distinguish pervasive and persistent cyclical movements of the economy from brief and fully reversible shocks. ${ }^{15}$

The regime switching model provides probabilities that can be used as prediction rules. In particular, historical turning points are dated using smoothing probabilities, which are obtained by backward recursion based on full

\footnotetext{
${ }^{15}$ According to Burns and Mitchell's (1946) definition of business cycle, a full cycle should have a minimum duration of at least one year and a maximum of 10 to 12 years.
} 
sample information, $\operatorname{Prob}\left(S_{t}=j \mid I_{T}\right), j=0,1 .^{16}$ Business and growth cycles chronologies are then determined using two criteria to define a turning point. First, from the frequency distribution of the probabilities, a peak occurs if the probabilities of recessions or slowdowns fall above their mean plus onehalf their standard deviation. This criterion tracks turning points according to their specific frequency distribution. Second, a peak occurs if the smoothed probabilities are greater than or equal to $50 \%$. That is, the economy is assumed to be in a recession if $P\left(S_{t}=0 \mid I_{T}\right) \geq P\left(S_{t}=1 \mid I_{T}\right)$. These two methods yield the same business and growth cycle turning point dating.

The resulting chronology is compared to the ones obtained from two alternative non-parametric procedures. First, Bry and Boschan's (1971) routine is applied to determine turning point dates. ${ }^{17}$ Bry and Boschan (B-B) formalized the NBER dating rules into a computer routine, which has been refined by Haywood (1973) to include an amplitude criterion. ${ }^{18}$ Second, turning points are obtained applying the rule of thumb of two consecutive quarters of decrease in GDP. As examined below, the turning points from these two methods are very similar to the ones obtained from the smoothing probabilities.

Tables 1 and 3 show the maximum likelihood estimated parameters for growth cycles and business cycles, respectively. The coefficients of the Markov states are statistically significant for both models, and capture switches and asymmetries across different cycle phases of the Brazilian economy. In particular, state 0 displays a low or negative mean and a shorter average duration, which is associated with economic slowdowns and recessions, respectively. State 1 exhibits a positive mean and longer average duration, depicting the features of high growth phases and expansions.

\footnotetext{
${ }^{16}$ For monitoring turning points on a current basis, however, the filtered probabilities should be used instead (as done in section 4), which give at time the probability of the Markov state using only information available at $t$.

${ }^{17}$ Harding generously provided his code for this program.

${ }^{18}$ The main steps of the B-B routine are: the data are smoothed after outliers are discarded; preliminary turning points are selected and compared with the ones in the original series; duration of the phases is checked and if it is below six months the turning points are disregarded; amplitude criterion is applied, based on a moving standard deviation of the series. In the end, the program selects turning points that would be easily picked simply by visual inspection.
} 


\section{The Brazilian growth cycle}

Figure 1 plots the estimated smoothed probabilities of high growth phases and the growth rate of real GDP in the last century. For the annual frequency, the probabilities capture a dichotomous pattern in the series associated with high and low economic growth phases. State 1 is characterized by a high production mean rate $\left(\mu_{1}=7.4 \%\right.$ per year $)$, while state 0 displays a low average growth rate $\left(\mu_{0}=1.15 \%\right.$ per year $)$, as seen in table 1 . The transition probabilities $\operatorname{Prob}\left[s_{t}=i \mid s_{t-1}=i\right]=p_{i i}$ are the probabilities of staying in state $i$ given that the economy is in state $i$. Their estimates are highly significant and the probability of staying in a high growth phase, $p_{11}=0.77$, is higher than the probability of staying in a slowdown, $p_{00}=0.66$. That is, on average, high growth phases last 4.4 years in Brazil and are more persistent than slowdowns, which last around three years. ${ }^{19}$

Figure 1

Growth rate of the Brazilian real GDP ( - ) and smoothed probabilities of high growth (---), annual data: 1990-99

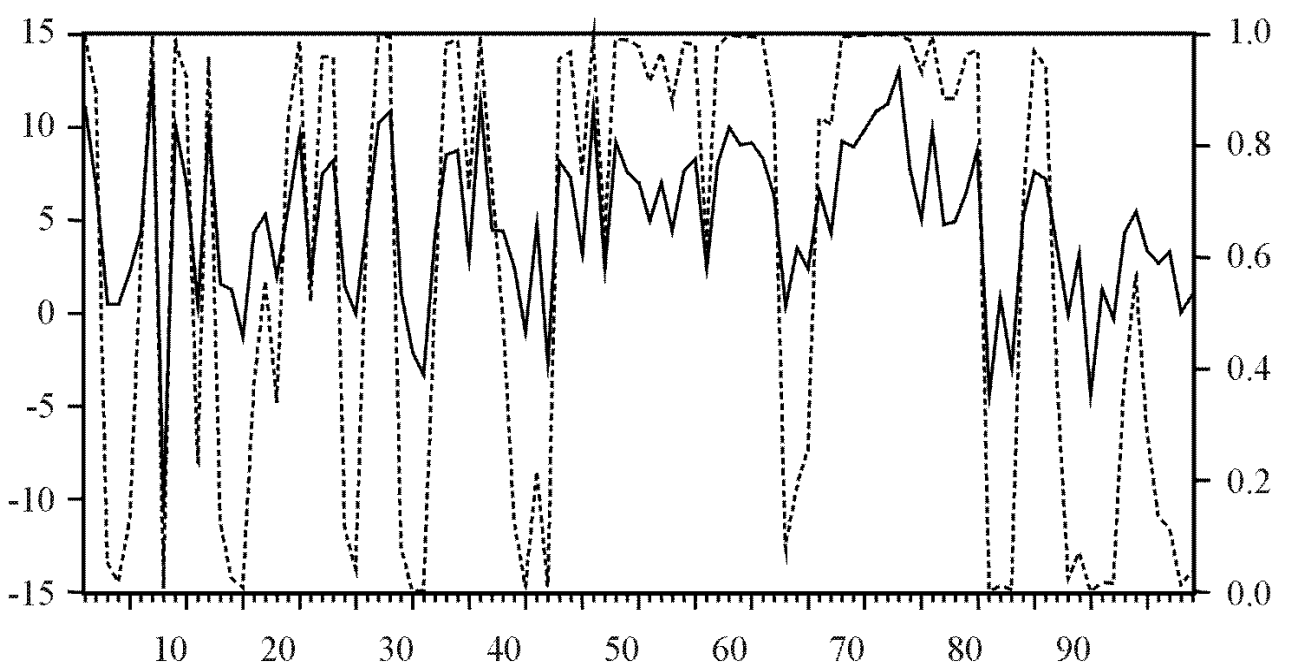

\footnotetext{
${ }^{19}$ The expected duration of slowdowns can be inferred by the transition probabilities using the formula: $\sum_{k=1}^{\infty} k p_{00}^{k-1}\left(1-p_{00}\right)=1 /\left(1-p_{00}\right)$.
} 
Table 1

Maximum likelihood estimates

(Annual data: 1901-99)

\begin{tabular}{lclc}
\hline Parameters & \multicolumn{3}{c}{ Parameters } \\
\hline$\mu_{1}$ & 7.432 & $p_{11}$ & 0.774 \\
& $(0.548)$ & & $(0.082)$ \\
$\mu_{0}$ & 1.148 & $p_{00}$ & 0.665 \\
& $(0.649)$ & & $(0.106)$ \\
$\sigma^{2}$ & 7.886 & & \\
& $(1.619)$ & & \\
\hline $\log L(\theta)$ & -185.053 & & \\
\hline
\end{tabular}

Note: Asymptotic standard errors in parentheses.

Figure 2 plots the smoothed probabilities of slowdowns and the resulting dating of the Brazilian growth cycles. Over the last century, Brazil experienced eleven growth cycles. Figure 3 contrasts the growth rate of real production with the growth cycle dating, the average annual growth (4.8\%) and bands corresponding to the mean plus/minus the standard deviation (4.4\%). The smoothed probabilities endogenously define slowdowns as periods in which annual growth reaches below $0.4 \%$ (mean minus standard deviation).

Figure 2

Smoothed probabilities of slowdowns (-) and the Brazilian growth cycle dating. Shaded area corresponds to slowdowns; annual data: 1990-99

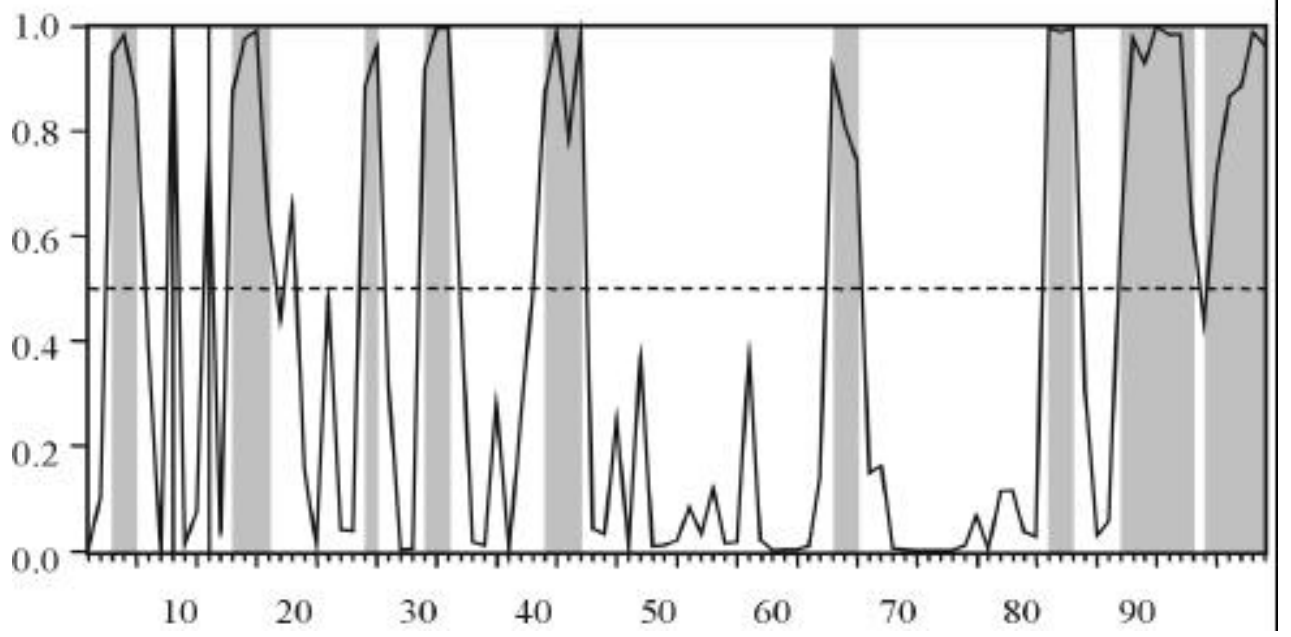


Figure 3

Growth rate of the Brazilian real GDP (-) and low growth phases (shaded area) Bands are the mean plus/minus the standard deviation of the growth rate of real production

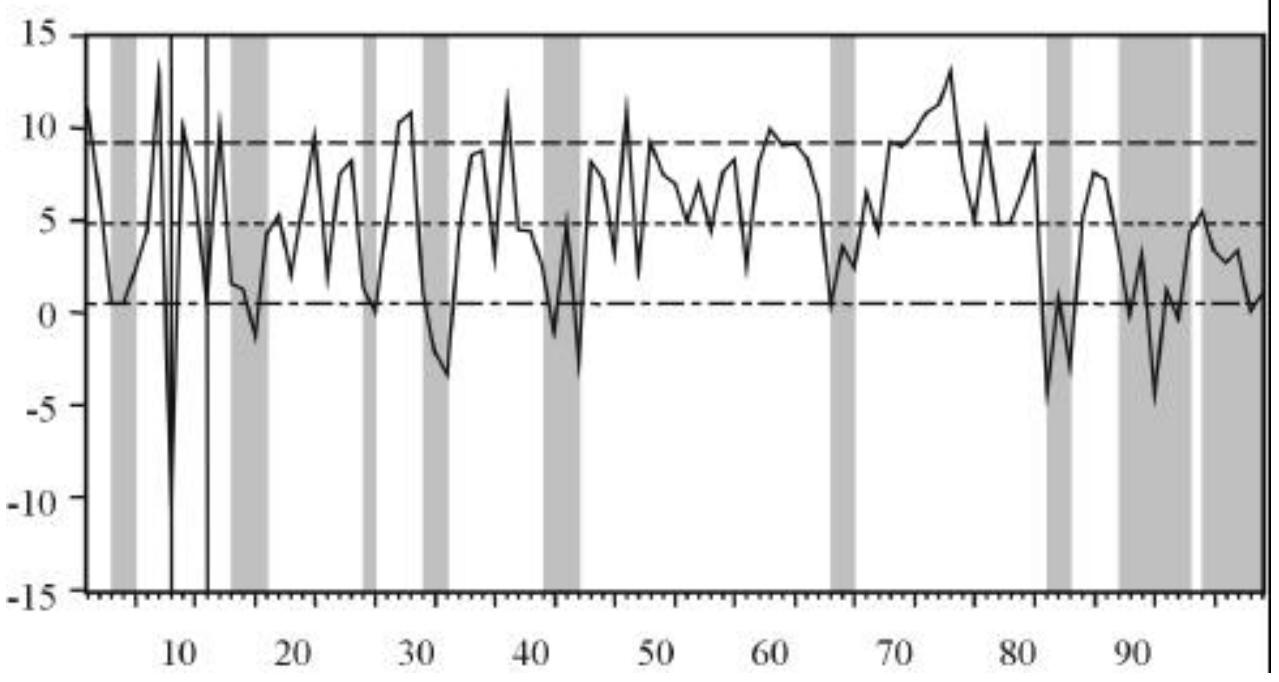

Table 2 reports dating of the Brazilian growth cycle phases using the smoothed probabilities and the Bry-Boschan routine. Both metrics used to identify turning points lead to very similar dating of growth cycles. The only difference is that the B-B program does not pick up the 1908 slowdown. The reason is that the program discards outliers, and this slowdown was the most severe downturn in the century.

There were seven slowdowns in the first half of the sample and four in the second. The most abrupt declines in the real Brazilian production occurred in 1908, 1981, and 1990. Until the 1940s, slowdowns were more frequent and had shorter duration (figures 2 and 3 ). In fact, in the beginning of the century the economy was much more volatile, reflecting great uncertainty during the distressed times comprising the two world wars and the Great Depression. ${ }^{20}$

\footnotetext{
${ }^{20}$ This can also be a partial result of the measurement of the annual GDP data, which was obtained from FGV. From 1940 on, this series corresponds to GDP as compiled by the IBGE. From 1900 to 1939 the data used correspond to a proxy of GDP obtained from Contador and Haddad (1975). The series were adjusted by FGV for compatibility using several statistical techniques.
} 
Table 2

Dating of growth cycle turning points

(Annual frequency: 1901-99)

\begin{tabular}{cccc}
\hline \multicolumn{2}{c}{$\begin{array}{c}\text { Smoothed } \\
\text { Probabilities }\end{array}$} & \multicolumn{2}{c}{ Bry-Boschan } \\
\hline Peak & Trough & Peak & Trough \\
\hline 1903 & 1905 & 1903 & 1905 \\
1908 & 1908 & - & - \\
1911 & 1911 & 1911 & 1911 \\
1913 & 1916 & 1913 & 1916 \\
1924 & 1925 & 1924 & 1925 \\
1929 & 1931 & 1929 & 1931 \\
1938 & 1942 & 1938 & 1942 \\
1963 & 1965 & 1963 & 1965 \\
1981 & 1983 & 1981 & 1983 \\
1987 & 1993 & 1987 & 1993 \\
1995 & 1999 & 1995 & 1999 \\
\hline
\end{tabular}

Note: Peaks are the beginning of slowdowns and troughs mark their end.

The first slowdown of the century started in 1903 and lasted three years. This was followed by two short slowdowns of one-year duration in 1908 and in 1911. During the six years of the World War I, from 1914 to 1918, the Brazilian economy was mostly in a slowdown. The economy was also affected by the Great Depression and World War II, entering in a low growth phase between 1929 and 1931, and between 1938 and 1942.

In the second half of the century, Brazilian slowdowns exhibited a longer duration and were much less frequent. In fact, three out of the four slowdowns during this period occurred in the 1980s and 1990s (figures 2 and 3). Between 1945 and 1981, the Brazilian economy experienced a long period of economic prosperity. Except for a slowdown between 1963 and 1965, which coincided with times of political instability and the military coup, the economy grew at a high pace for almost 40 years. The high growth phases in the $1950 \mathrm{~s}$ and 1960s are concurrent with the Brazilian import substitution program and heavy public investment on infrastructure. This period also parallels the long expansion in the US and OECD countries during the 1960s. In the 1970s, the oil crisis led many countries to gear back their economies to adjust for the impact of this supply shock. However, Brazil did not follow the tune. Public investment was at all times high, and the economy grew at high annual rates, between $7 \%$ and $12 \%$, characterizing the period known as the "Brazilian economic miracle." 
The second oil shock in 1979 and the credit crunch in the early 1980s deeply affected the Brazilian economy and other Latin American countries. One of the reasons of this liquidity constraint were the changes in the procedures of the US Federal Reserve Bank. From October 1979 to the end of 1981, the Fed targeted only the rate of growth of money supply, which caused a substantial increase in the level and volatility of the interest rates. In fact, the US interest rates increased from an average of $4 \%$ between 1954 and 1979, to an average of $12 \%$ between 1979 and 1981. Increases in oil prices and interest rates led to a severe burden on the highly indebted Latin American countries, which was intensified by the Mexican moratorium in 1982. This induced lending banks and international institutions to restrict credit even further, aggravating the liquidity situation of the Latin American countries. In this period Brazil entered a low growth phase, between 1981 and 1983.

In the late 1980s and first half of the 1990s the Brazilian economy experienced very turbulent times, comprising a disrupting hyperinflationary process and six major stabilization plans aiming to control it. These changes in policy regimes engendered structural breaks in the economy and created a very uncertain and unsuitable environment for economic growth. Figure 4 plots inflation as measured by the broad consumer price index (IPCA) and the stabilization plans in the 1980s and 1990s. Accordingly, the Brazilian economy entered in two long periods of slowdown: one following the Cruzado Plan, from 1987 to 1993, and the other following the Real Plan, from 1995 to 1999. That is, in the last 13 years the Brazilian economy experienced only one year of accelerated growth, in 1994.

The shape of the Brazilian growth cycle is further examined using measures of duration, amplitude, and cumulative movements within phases, as proposed in Harding and Pagan (2001). ${ }^{21}$ Table 3 summarizes the results for

\footnotetext{
${ }^{21}$ These measures are calculated based on a dummy $0 / 1, S_{t}$, which takes the value 0 during low growth phases. The average duration of a slowdown is obtained by estimating the equation $S_{t}=\alpha+\beta S_{t-1}$ and using the estimated parameters to compute $1 /(1-\hat{\alpha}-\hat{\beta})$. The average amplitude of a slowdown can be obtained by regressing the log first difference of GDP on $S_{t}$. The cumulative movements measures the cumulated losses in output from peak to trough, compared to the previous peak, and can be approximated by half of the product between the amplitude and duration. For more details, see Harding and Pagan (2001).
} 
the dating obtained from the B-B method and the Markov switching model (columns 1 and 2). Column 3 gives the average results implied by the Markov switching model derived directly from the estimated parameters reported in table 2. The results for both methods are very similar. The duration of high growth phases is longer and the amplitude of movements is larger than for low growth phases. In addition, the cumulation of losses in output during slowdowns is much smaller than the cumulation of gains during high growth phases. That is, when the Brazilian economy undergoes prosperous periods the cumulative increase in GDP from the beginning to the end of the phase is very large, which points to the importance of policies that promote growth.

\section{Figure 4}

IPCA inflation ( - ) and stabilization plans (shaded area)

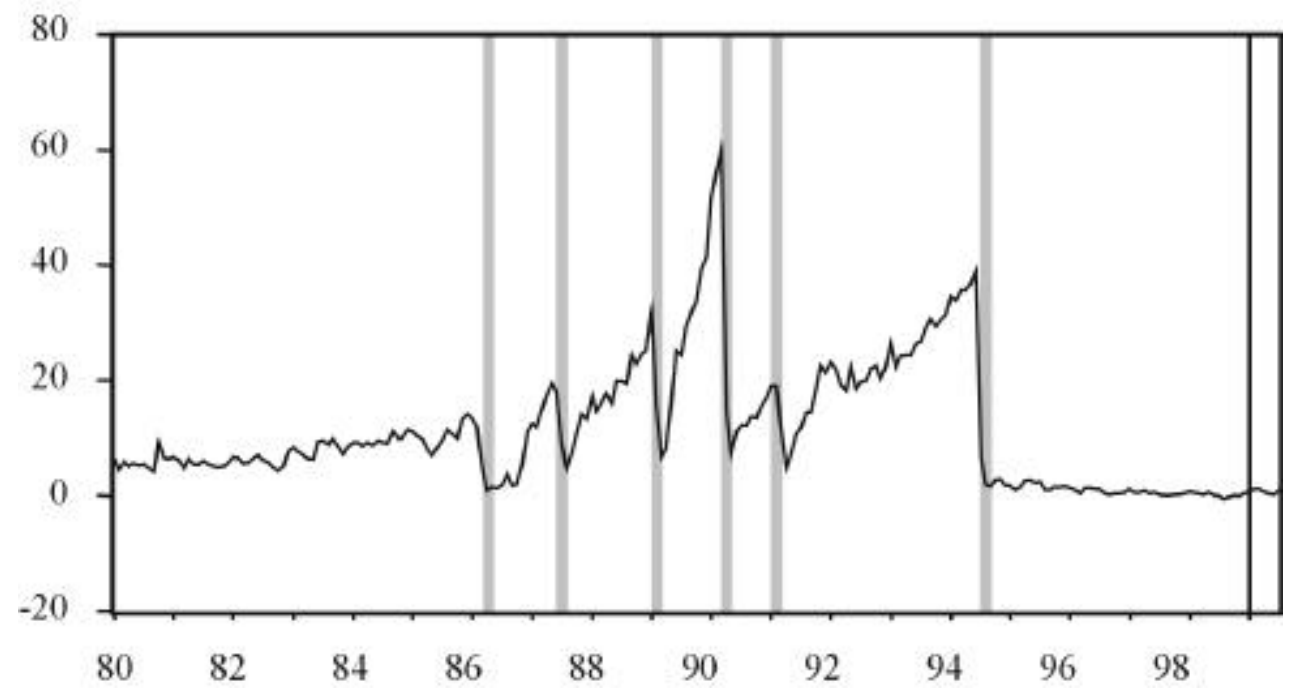

The last row of table 3 shows the inverse of the coefficient of variation (the ratio of the mean of a random variable to its standard deviation), which summarizes cycle characteristics such as its frequency, duration, and amplitude. This ratio is equal to 1.07 for actual changes in GDP, while it is equal to 1.06 for the parameters of the Markov switching model. That is, the Markov switching model represents very closely the shape of the actual Brazilian growth cycle. 
Table 3

The characteristics of the Brazilian growth cycle

\begin{tabular}{lccc}
\hline & B-B & MS & $\begin{array}{c}\text { MS - model } \\
\text { parameters }\end{array}$ \\
\hline Mean duration (years) & & & \\
$\quad$ Low growth & 3.89 & 3.60 & 3.00 \\
High growth & 6.40 & 5.73 & 4.40 \\
Mean amplitude $(\%)$ & & & 1.15 \\
Low growth & 0.89 & 0.75 & 7.43 \\
High growth & 7.10 & 7.38 & - \\
Cumulation $(\%)$ & & & - \\
Low growth & 1.73 & 1.35 & \\
High growth & 22.72 & 21.14 & 1.06 \\
$\mu / \sigma \quad$ & & 0.41 \\
Full sample & - & - & 2.65 \\
Low growth & - & - & \\
High growth & - & - & \\
\hline
\end{tabular}

Note: $\mu / \sigma$ are the estimated first and second moments of $y_{t}$.

\section{The Brazilian business cycle}

At the quarterly frequency, the Markov model captures business cycle phases. Recessions can be interpreted as more severe slowdowns, while expansions are periods of moderate growth. Figure 5 shows the smoothed probabilities of recessions and slowdowns from 1980:2 to 2000:01. ${ }^{22}$ Generally, slowdowns start before the onset of recessions and end after the trough, which implies that recessions are more frequent than slowdowns. While slowdowns correspond to periods of low economic growth, recessions correspond to more severe downturns, in which the economy displays negative growth. In fact, recessions were so frequent in the last 20 years that in most of this period the economy was in a slowdown phase.

Table 4 shows the maximum likelihood estimates for the quarterly data. State 0 has a negative long run mean rate $\left(\mu_{0}=-1.5 \%\right.$ per quarter or $-6 \%$ per year), and a short duration of 2.5 quarters $\left(p_{00}=0.51\right) .{ }^{23}$ State 1 has

\footnotetext{
${ }^{22}$ For comparison, the annual probabilities were converted to quarterly frequency in this figure using the local quadratic interpolation method with average matched to the observed data.

23 "Long run" means that if the state no longer changed.
} 
a positive mean rate $\left(\mu_{1}=1.4 \%\right.$ per quarter or $5.6 \%$ per year $)$ with a longer average duration of five quarters $\left(p_{11}=0.8\right)$, which characterizes expansions. That is, the model captures asymmetries in the stages of business cycles, in which recessions are abrupt and shorter, while expansions are more gradual and longer.

Figure 5

Smoothed probabilities of recessions at quarterly $(-)$ and annual frequencies (---), 1980:2-1999:4

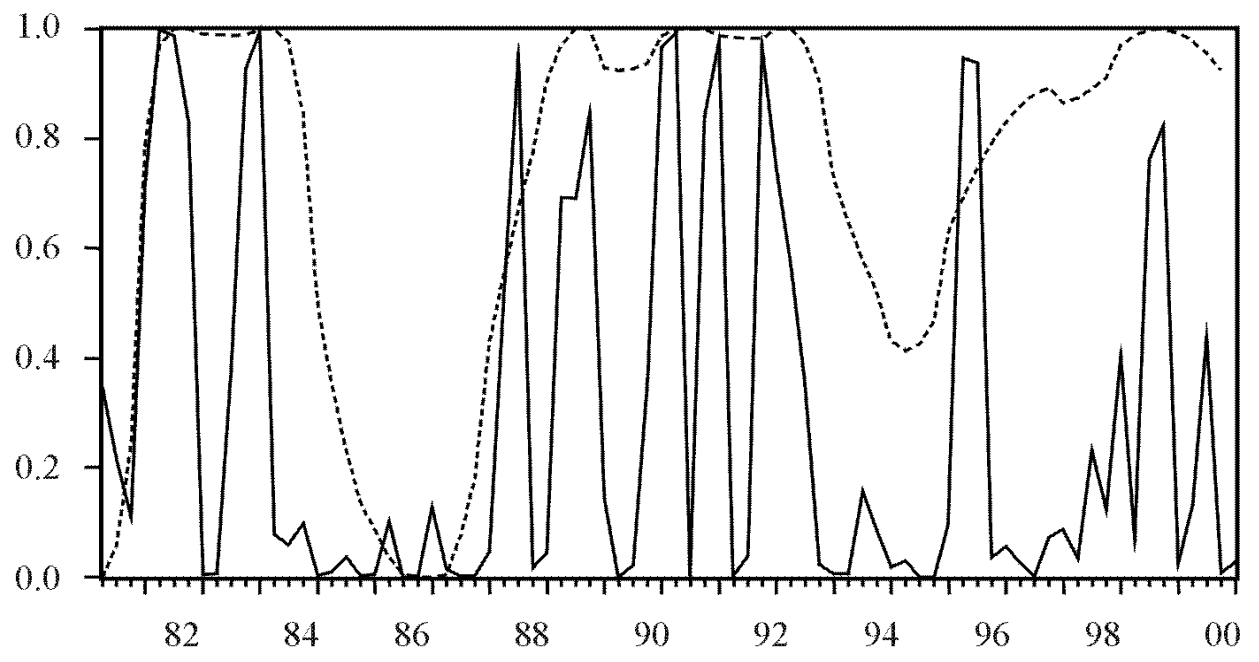

Table 4

Maximum likelihood estimates

(Quarterly data: 1980:2-2000:1)

\begin{tabular}{lllc}
\hline Parameters & \multicolumn{3}{c}{ Parameters } \\
\hline$\mu_{1}$ & 1.370 & $p_{11}$ & 0.799 \\
& $(0.265)$ & & $(0.082)$ \\
$\mu_{0}$ & -1.555 & $p_{00}$ & 0.515 \\
& $(0.464)$ & & $(0.135)$ \\
$\sigma^{2}$ & 1.747 & & \\
& $(0.402)$ & & \\
\hline $\log L(\theta)$ & -87.528 & & \\
\hline
\end{tabular}

Note: Asymptotic standard errors in parentheses. 
Table 5 reports the dating of the Brazilian business cycle using smoothed probabilities, B-B routine, and the rule of two consecutive quarters of decrease in GDP. These dating procedures generate a very similar chronology for business cycles. A minor difference is that the smoothed probabilities identify the beginning of the 1982 and the 1990 recessions as one quarter after what is predicted by the other methods. Although the smoothed probabilities increase before these recessions, indicating an economic slowdown, the model endogenously identifies the beginning of recessions as quarters in which the economy actually enters a period of negative growth.

\section{Table 5}

Dating of the Brazilian business cycle turning points at quarterly frequency: 1980:I-2000:I

\begin{tabular}{|c|c|c|c|c|c|}
\hline \multicolumn{2}{|c|}{$\begin{array}{c}\text { Smoothed } \\
\text { probabilities }\end{array}$} & \multicolumn{2}{|c|}{ Bry-Boschan } & \multicolumn{2}{|c|}{$\begin{array}{c}\text { Two consecutive } \\
\text { declines }\end{array}$} \\
\hline Peak & Trough & Peak & Trough & Peak & Trough \\
\hline 1981:I & 1981:IV & 1981:I & 1981:IV & 1981:I & 1981:IV \\
\hline 1982:IV & 1983:I & 1982:III & 1983:I & 1982:III & 1983:I \\
\hline 1987:II & 1987:III & 1987:II & 1987:III & 1987:II & 1987:III \\
\hline 1988:II & 1988:IV & 1988:II & 1988:IV & 1988:II & 1988:IV \\
\hline 1990:I & 1991:I & 1990:I & 1991:I & 1989:IV & 1991:I \\
\hline 1991:IV & 1992:II & 1991:IV & 1992:II & 1991:IV & 1992:III \\
\hline 1995:II & 1995:III & 1995:II & 1995:III & 1995:II & 1995:III \\
\hline 1998:I & 1998:IV & 1998:I & 1998:IV & 1998:I & 1998:IV \\
\hline
\end{tabular}

Note: Peaks are the beginning of recessions and troughs are their end.

This can be seen in figures 6 and 7, which plot the estimated smoothed probabilities of recessions and the growth rate of real GDP against expansion and recession phases. The quarterly average growth rate of GDP is 0.49 with a 2.3 standard deviation. The probabilities signal recessions as times in which the economy reaches a growth below the sample average minus the standard deviation $(-1.79)$.

Figure 8 compares these results with the smoothed probability of recessions obtained when the variance of changes in GDP is also allowed to switch between two regimes. These smoothing probabilities now reflect periods of high volatility. As it can be seen in the figure, the probabilities depict the uncertainty associated with bad times, which encompass a series of recessions. 
Figure 6

Smoothed probabilities of recessions (-) and dating of the Brazilian business cycle (shaded area)

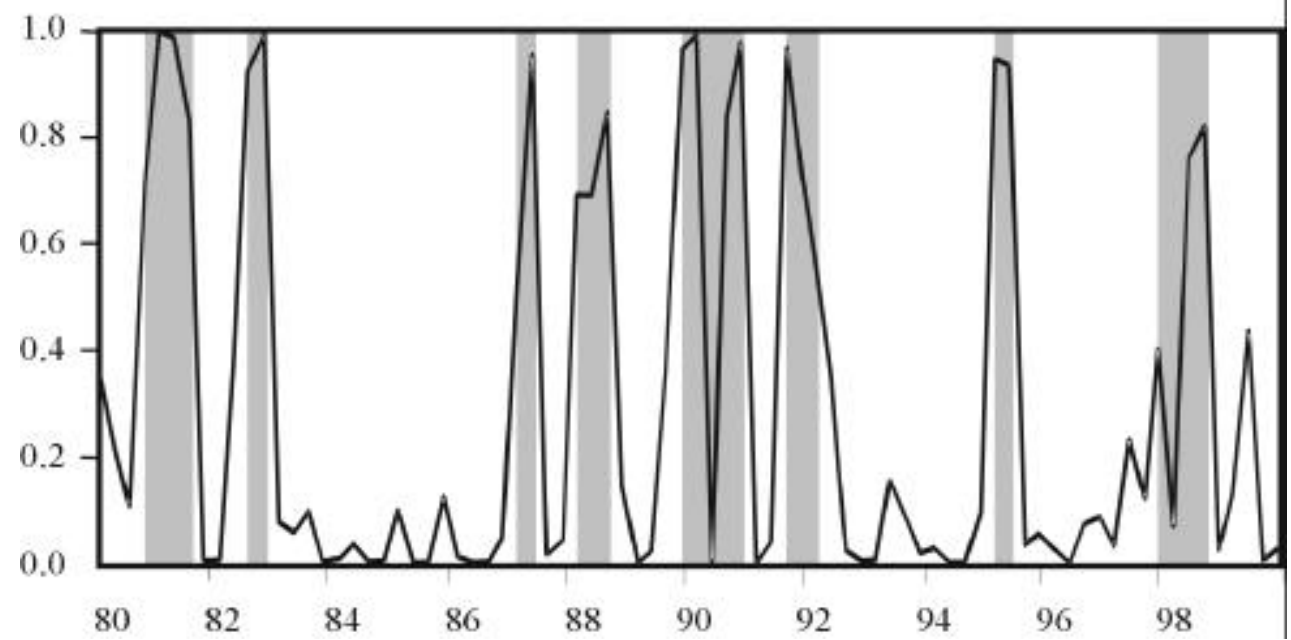

Figure 7

Growth rate of real GDP (-) and the Brazilian business cycle recessions phase (shaded area). Bands are the mean plus/minus the standard deviation of the growth rate of real GDP

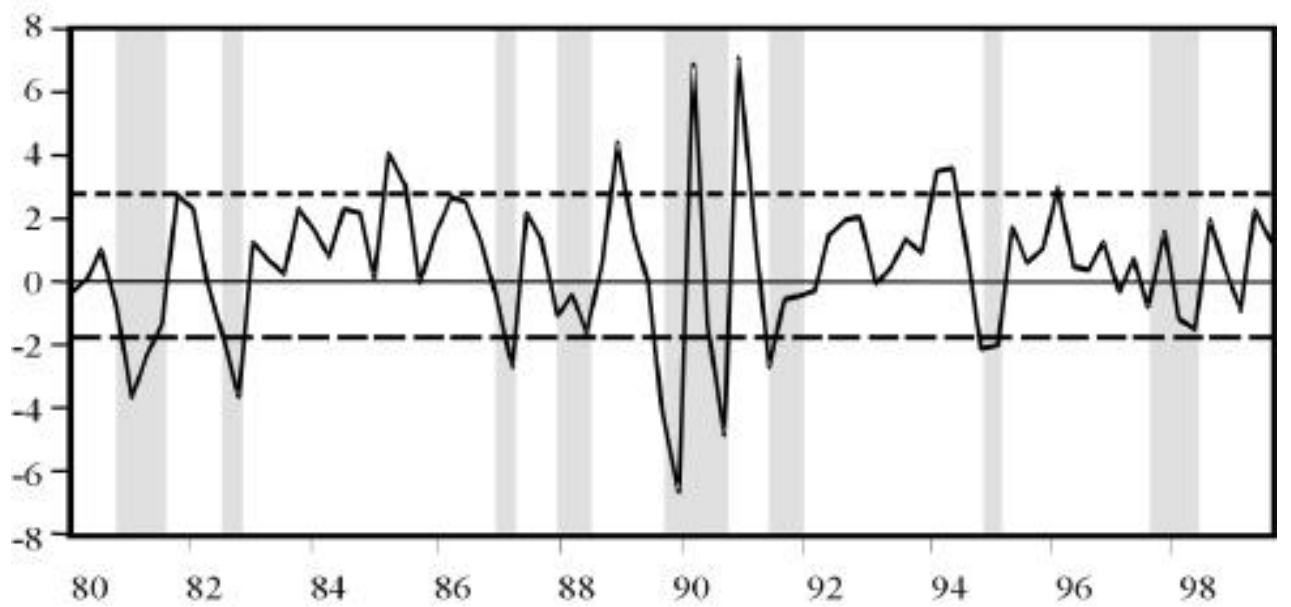

As seen in table 5, the Brazilian economy experienced eight recessions and nine expansions in the last 20 years. Several recessions were caused by external shocks. In the early 1980s, there were two recessions of short duration that occurred very close to each other. The first one started in the first 
quarter of 1981 and lasted four quarters. The second one went on for only six months, during the fourth quarter of 1982 and first quarter of 1983 . These recessions in Brazil correspond to a worldwide contractionary economic period (see Chauvet \& Yu, 2000). Subsequently, the economy entered an expansion from 1983 to 1987 - the longest one in the last 20 years (16 quarters), when the Brazilian GDP grew at an average rate of $6.5 \%$ per year.

Figure 8

Smoothed probabilities of recessions from the MS AR $(0)$ in the mean (-), for the MS AR( $(0)$ in the mean and variance (--), and dating of the Brazilian business cycle (shaded area)

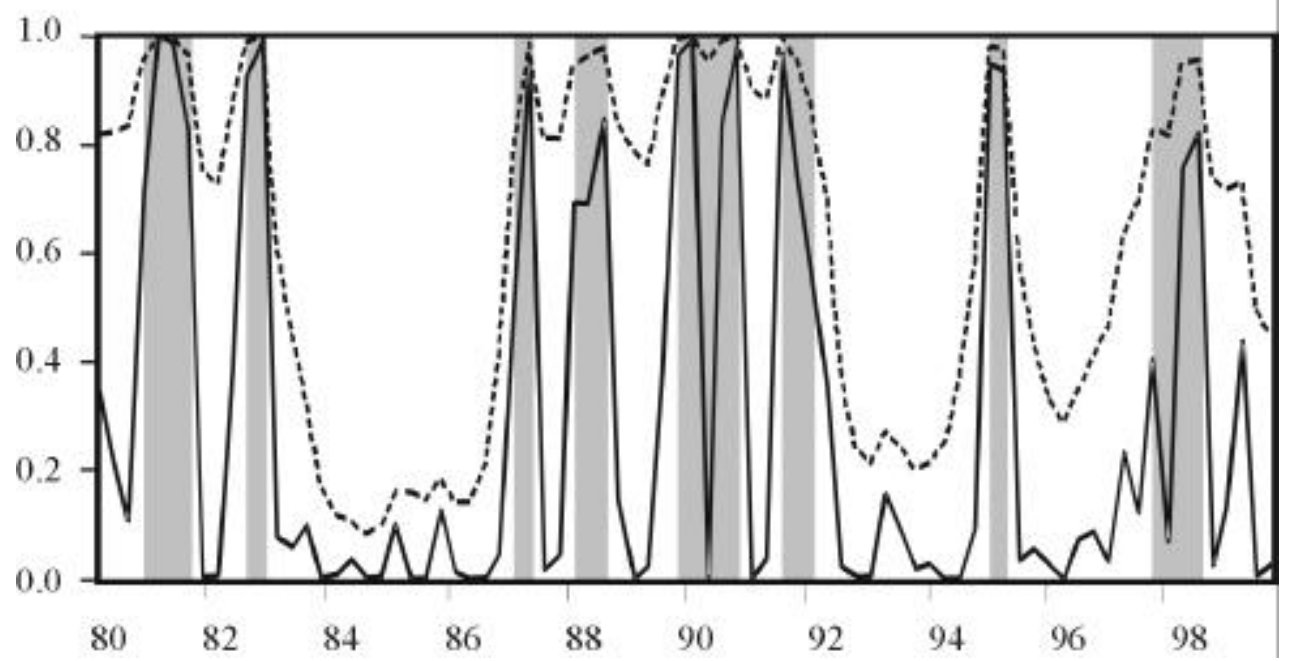

As seen in the previous section, from 1987 to 2000, the Brazilian economy was in a low growth phase, except for 1994. During this same period the economy experienced six recessions (negative growth) of relative short duration, generally associated with the implementation of stabilization plans. In fact, in the five years between 1987 and 1992, there were five severe economic recessions. The first recession occurred in the second and third quarters of 1987, coinciding with the Bresser Plan. Inflation growth did not subside in spite of the successive plans, and in the second quarter of 1988 until the end of 1988 the economy entered another recession. In the first quarter of 1990, the Collor Stabilization Plan gave rise to the most severe recession in the sample (-8.1\% annual growth rate) associated with high volatility in the growth rates of real GDP, which lasted for one year. Subsequently, the economy entered a short-lived recovery in 1991, but it lasted only six months. In fact, another recession hit the economy in the fourth quarter of 1991, lasting until the second 
quarter of 1992. At this time the economy shrunk at an annual negative rate of $5.1 \%$. In the third quarter of 1992 the economy finally entered a period of relative calmness, coinciding with the impeachment of president Collor.

In the last nine years Brazil was in an expansion period $74 \%$ of the time. The economy experienced only two short-lasted recessions in this period, which were associated with international shocks. Between the third quarter of 1992 and that of 1995 (12 quarters), the economy grew at an average annual rate of $5.7 \%$. In fact, in 1994 the economy entered a period of high growth phase, when GDP grew at an annual average of $9.25 \%$. In the second and third quarters of 1995 there was a recession associated with the Mexican crisis and a subsequent increase in the domestic interest rates. From the fourth quarter of 1995 until the second quarter of 1998 the economy was in an expansion phase for 11 quarters, with a modest average growth rate of $3.4 \%$ per annum.

The last four years of the sample were marked by high volatility in GDP growth, as the Brazilian economy was hit by several external shocks. This can be seen in the unusual ups and downs of the smoothed probabilities of recessions during this period, in figure 6 . The Asian crisis had a corresponding mild increase in the probabilities of recession in the third quarter of 1997 and in the first quarter of 1998. Although the economy recovered in the second quarter of 1998, this is not considered a full expansion due to its short duration. Given the rules adopted with respect to the duration of cycles, all dating methods point to a recession starting in the first quarter of 1998 and ending in the last quarter of this year.

The Russian crisis in July 1998 increased the perceived risk of emergent market economies, which contributed to a currency crisis in Brazil in the first quarter of 1999. In an attempt to avoid the crisis, the Central Bank increased interest rates in almost 85\% in the third and forth quarters of 1998, sustaining a recession during this period. However, contrarily to widespread expectations, a severe recession did not follow the currency crisis, and the economy entered a modest recovery already in the first quarter of 1999 .

More recently, the economy has grown at an average annual rate of 3.9\% in the last five quarters of the sample. ${ }^{24}$ In the fourth quarter of 1999 the growth rate of real GDP was $8.9 \%$ per year while in the first quarter of 2000

\footnotetext{
${ }^{24}$ The Brazilian GDP decreased in the third quarter of 1999, as reflected in the smoothed probabilities (figure 6). Again, this is not considered a recession due to its very short duration.
} 
the annual growth was $4.9 \%$. The smoothed probabilities shown in figure 6 indicate a $99 \%$ and a $97 \%$ probability of the economy being in an expansion in the last quarter of 1999 and first quarter of 2000.

The shape of the Brazilian business cycle in terms of duration, amplitude, and cumulative changes within phases is summarized in table 6 , for all the dating methods implemented. ${ }^{25}$ As it can be observed, the results for all methods are closely related. The average duration of recessions is smaller than the duration of expansions. With respect to amplitude, recessions are generally deeper than expansions for all methods, except for the rule of two quarters of decline. Finally, the cumulation of losses in output during recessions is smaller than the cumulation of gains during expansions, as in the case of growth cycles. That is, the cumulative increase in GDP from the beginning to the end of an expansion relatively to its previous peak is larger than the losses from a recession.

Table 6

The characteristics of the Brazilian business cycle

\begin{tabular}{lcccc}
\hline & $\begin{array}{c}\text { Two } \\
\text { declines }\end{array}$ & B-B & MS & $\begin{array}{c}\text { MS - model } \\
\text { parameters }\end{array}$ \\
\hline Mean duration (quarters) & & & & \\
$\quad$ Recessions & 3.22 & 3.25 & 3.12 & 2.50 \\
$\quad$ Expansions & 6.25 & 6.50 & 6.75 & 5.00 \\
Mean amplitude (\%) & & & & \\
$\quad$ Recessions & 1.45 & 1.55 & 1.69 & 1.55 \\
$\quad$ Expansions & 1.57 & 1.51 & 1.48 & 1.37 \\
Cumulation (\%) & & & & \\
$\quad$ Recessions & 2.33 & 2.52 & 2.50 & - \\
$\quad$ Expansions & 4.91 & 4.91 & 4.99 & - \\
$\mu / \sigma$ & & & & \\
$\quad$ Full sample & - & - & - & 0.48 \\
Low growth & - & - & - & -1.17 \\
High growth & - & - & - & 1.04 \\
\hline
\end{tabular}

Note: $\mu / \sigma$ are the estimated first and second moments of $y_{t}$.

${ }^{25}$ These measures were calculated as in table 3. 
The last row of table 6 shows the inverse of the coefficient of variation for the Markov switching model. The coefficient of variation from the model is relatively close to the actual data. This ratio is equal to 0.48 using the parameters of the Markov switching model and equal to 0.27 for actual changes in GDP. The difference comes from the fact that the variance of actual GDP is higher than the estimated by the model, while the mean values are very similar. In fact, most of this extra variance is related to the structural break caused by the Collor Plan in 1990/91.

As it will be discussed in the next section, the implied non-linear conditional mean in the Markov switching model generates some additional cyclical movements that are useful in replicating certain features of the business cycle. In fact, compared to alternative linear models, the Markov switching model captures much closer the variance of business cycles, specially around the breaks and recessions related to stabilization plans.

\section{Out-of-Sample Forecasting}

In this section the out-of-sample forecasting ability of the Markov switching model is compared to linear autoregressive models. The idea here is not to find the best forecasting model for changes in quarterly GDP. Instead, the goal is to examine whether considering of the nonlinear regime switching process improves the forecasting performance for changes in GDP compared to linear counterparts.

Two linear models for changes in GDP are used for comparison with the Markov switching model (henceforth model A): an ARMA $(1,1)$ which was selected using Box-Jenkins procedure (model B), and an autoregressive process AR(5) (model C), where the number of lags was selected using Schwarz criterion. The models are first estimated from 1980:2 up to 1989:1, and then recursively re-estimated out-of-sample for each subsequent quarter from 1989:2 to 2000:1.

The analytic forms of predicted one-step ahead mean and filtered probabilities for the Markov switching model are as follows. The predicted mean at the first forecast date $\mathrm{T}+1=1989: 2$ is given by:

$$
\widehat{y}_{T+1 \mid T}=\widehat{\mu}_{T+1 \mid T}=\sum_{j=0}^{1} \mu_{j} P\left(S_{T+1}=j \mid y_{T}\right)
$$


the predicted filtered probability is:

$$
P\left(S_{T+1}=j \mid y_{T}\right)=\sum_{i=0}^{1} P\left(S_{T+1}=j \mid S_{T}=i\right) P\left(S_{T}=i \mid y_{T}\right)
$$

Notice that the one-step ahead filtered probability depends only on the current filtered probability and on the transition probability, given the independence assumption from the first-order process. Thus, the one-step-ahead predicted filtered probability of recession is:

$$
\begin{aligned}
P\left(S_{T+1}\right. & \left.=0 \mid y_{T}\right)=P\left(S_{T+1}=0 \mid S_{T}=0\right) * P\left(S_{T}=0 \mid y_{T}\right)+ \\
& +P\left(S_{T+1}=0 \mid S_{T}=1\right) * P\left(S_{T}=1 \mid y_{T}\right)
\end{aligned}
$$

At time $T+2=1989: 3$, one more observation of $y_{t}$ is added, and the Markov switching model is reestimated to obtain a new set of optimal parameters and current filtered probability. This procedure is repeated for each subsequent quarter up to the last observation in the sample, $T+3=1989: 4, \ldots, \mathrm{T}+44=$ 2000:1, to obtain the recursive one-step ahead forecasts of the filtered probability and the mean changes in GDP.

Table 7 reports the out-of-sample predictive performance for the different models analyzed. The Markov switching model displays a better out-ofsample forecasting performance than the linear models using several different statistics. The adjusted coefficient of determination $\left(\bar{R}^{2}\right)$ for model $\mathrm{A}$ is $71 \%$, while it is only $11 \%$ for model B, and $22 \%$ for model C. In addition, model A has a smaller root mean squared error (RMS), mean absolute error (MAE) and Theil inequality coefficient (Theil IC) compared to the other models. In particular, the variance proportion for the Markov switching model - which measures how far the forecast is from the variance of the actual series - is the smallest of three models. ${ }^{26}$ This corroborates previous findings in the literature, in which the nonlinearity of the Markov switching model is useful in replicating the variability of the business cycle. ${ }^{27}$ This can also be seen in

\footnotetext{
${ }^{26}$ The Theil IC is divided into three components: bias proportion, variance proportion, and covariance proportion. The bias and variance proportions measure, respectively, how far the mean and the variance of the forecast is from the mean and the variance of the actual series. The covariance proportion is obtained by residual as the three components add up to one. Thus, the smaller the bias and variance proportions the better the forecasts are, that is, most of the bias should be on the covariance proportion.

${ }^{27}$ See Harding and Pagan (2001) for some simulation results.
} 
figures 9, 10, and 11, which plot the one-step-ahead forecasts changes in GDP for models A, B, and C, respectively. Compared to the linear models, the Markov switching model tracks closer the variance of business cycles.

Table 7

Out-of-sample forecasting performance

\begin{tabular}{lccc}
\hline $\begin{array}{c}\text { Forecasting } \\
\text { performance }\end{array}$ & \multicolumn{3}{c}{ Out-of-sample: 1989.2-2000.1 } \\
& Model A & Model B & Model C \\
\hline $\bar{R}^{2}$ & 0.714 & 0.119 & 0.224 \\
$\mathrm{RMS}$ & 0.996 & 2.674 & 2.107 \\
$\mathrm{MAE}$ & 0.759 & 1.939 & 1.563 \\
Theil IC & 0.310 & 0.550 & 0.511 \\
Bias & 0.000 & 0.000 & 0.000 \\
Variance & 0.015 & 0.017 & 0.282 \\
Covariance & 0.985 & 0.983 & 0.718 \\
\hline
\end{tabular}

Note: model A - AR(0) MS; model B - ARMA(1,1); model C - AR(5).

Figure 9

Out-of-sample one-step-ahead forecasts of $\triangle \mathrm{GDP}$ from model A (-), and actual $\Delta$ GDP (---)

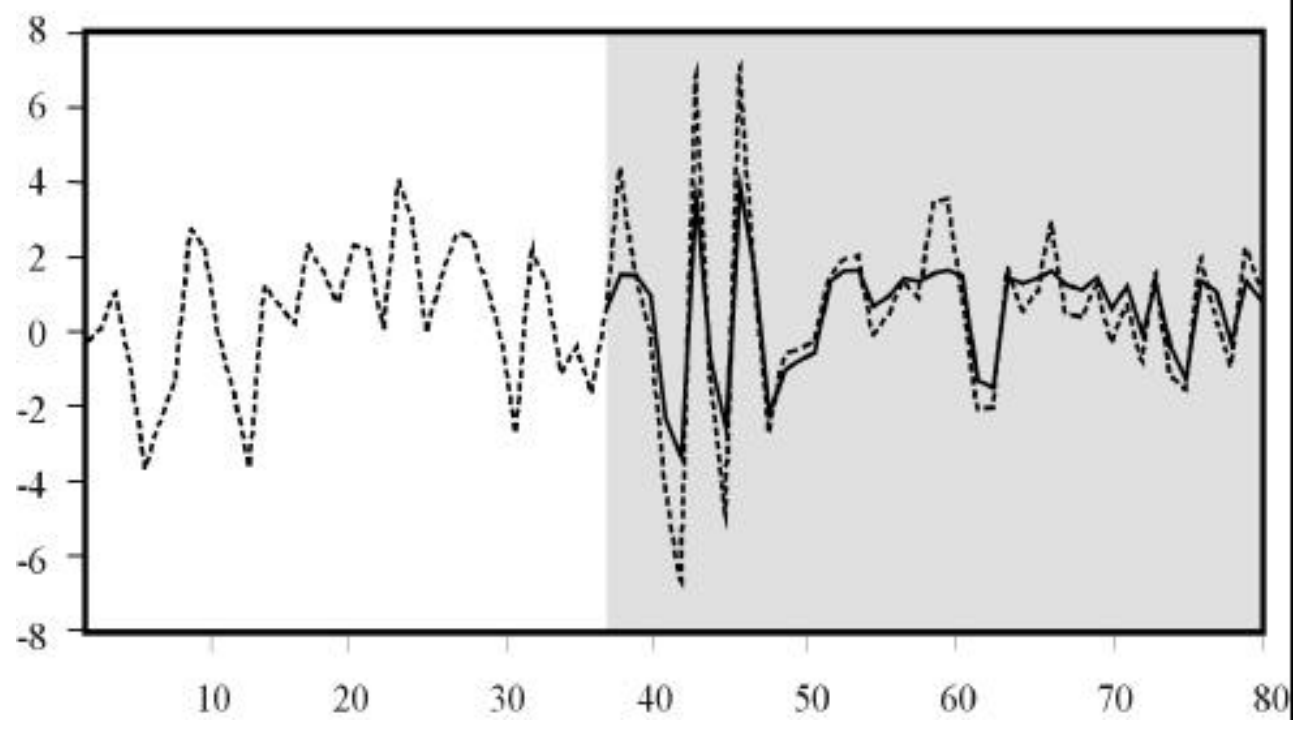


Figure 10

Out-of-sample one-step-ahead forecasts of $\triangle \mathrm{GDP}$ from model B (-), and actual $\triangle$ GDP (---)

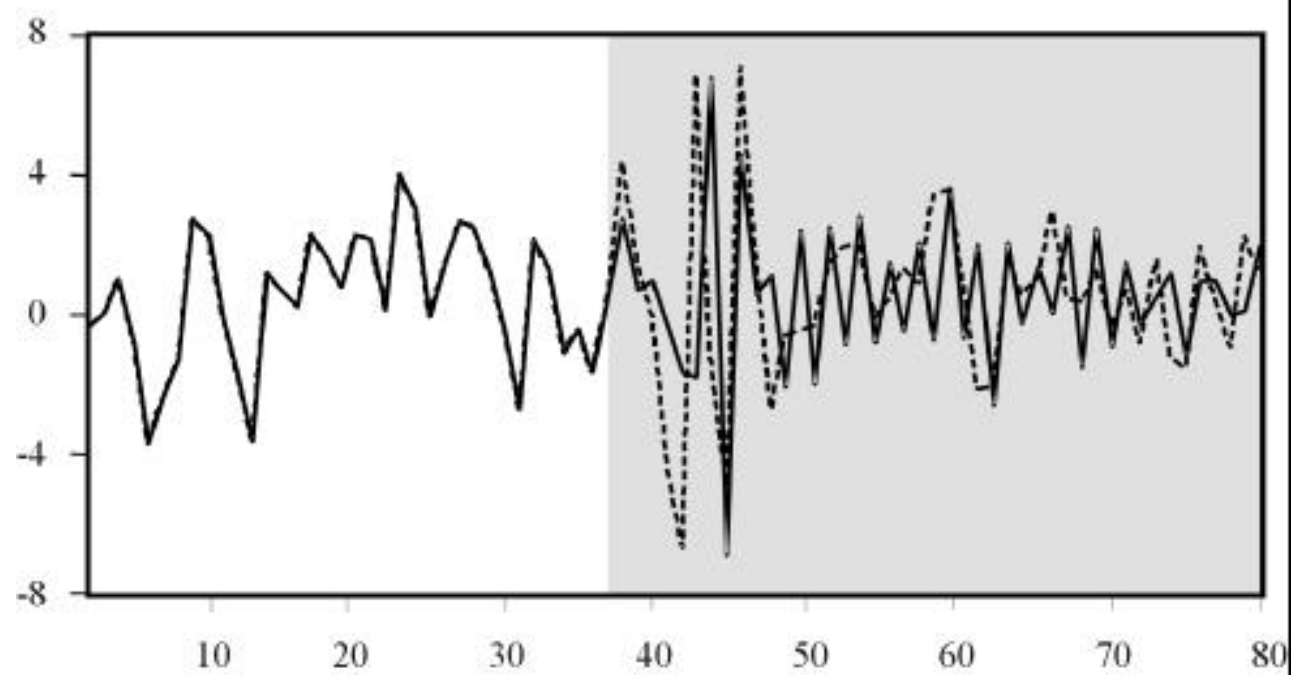

Figure 11

Out-of-sample one-step-ahead forecasts of $\triangle G D P$ from model C (-), and actual $\Delta$ GDP (---)

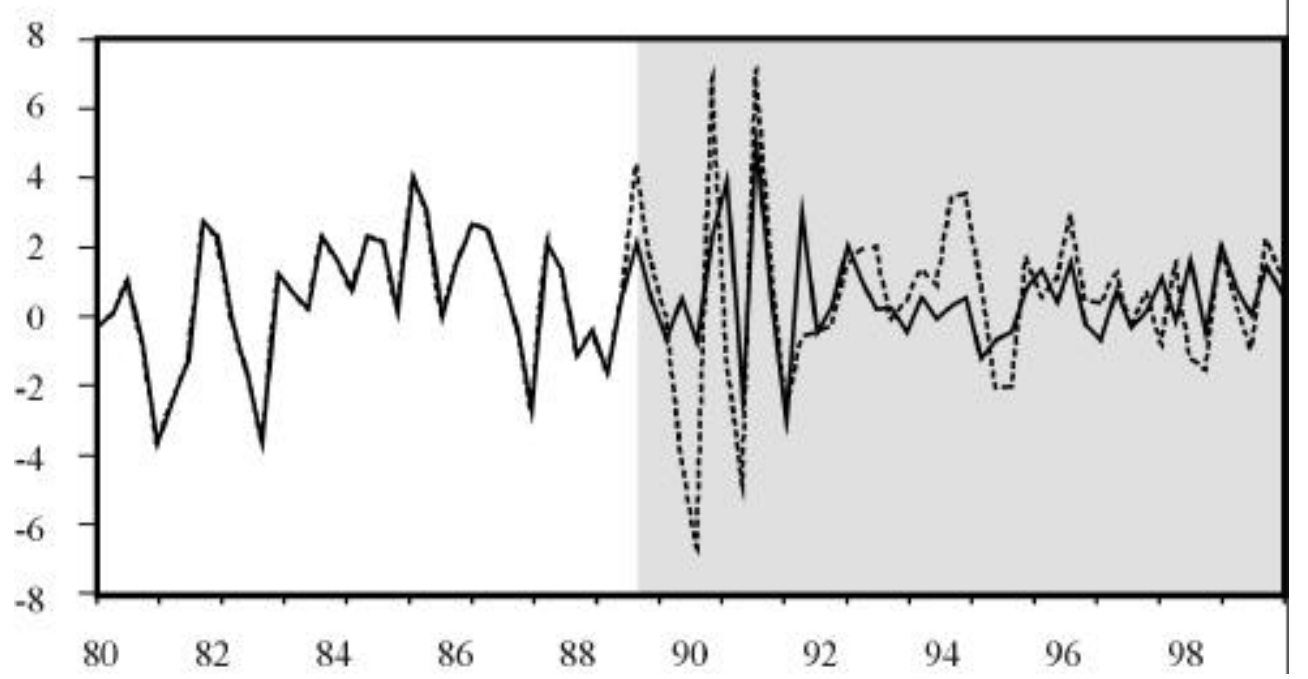




\section{Conclusions}

This paper uses several methods to date and analyze the Brazilian business and growth cycles. In particular, optimal probability inferences from a Markov switching model are used to define the different phases of cyclical economic fluctuations underlying real Brazilian production. The results are compared with several non-parametric dating rules, and all procedures yield very similar chronologies for the Brazilian economy. The resulting dating of the Brazilian business and growth cycles can be used as a reference point for construction and evaluation of the predictive performance of coincident, leading, or lagging indicators of economic activity. In addition, the filtered probabilities obtained from the Markov switching model allow assessment of the current state of the Brazilian economy on a timely basis. An early recognition of the economic transition to a new business cycle phase can be used for evaluation of the adequate strength and timing of countercyclical policies, reassessment of projected sales or profits by businesses and investors, or monitoring of inflation pressures, among other things.

All the methods used to date turning points capture asymmetries across different cycle phases of the Brazilian economy with respect to duration, amplitude, and cumulative changes within phases. In particular, the Markov model identifies a state with low or negative mean and a shorter average duration, which is associated with economic slowdowns and recessions. The other state exhibits a positive mean and longer average duration, which characterizes features of high growth phases and expansions. These asymmetries regarding duration, amplitude, and deepness across business cycle expansions and recessions are also observed in the OECD countries.

An out-of-sample forecasting exercise was implemented to compare the performance of the Markov switching model for changes in GDP with linear specifications, and it is found that the nonlinear model displays a better outof-sample forecasting performance than the linear models.

\section{References}

Albert, J. \& Chib, S. Bayesian analysis via gibbs sampling of autoregressive time series subject to Markov mean and variance shifts. Journal of Business and Economic Statistics, 11:1-15, 1993. 
Artis, M. J. ; Kontolemis, Z. G. \& Osborn, D. R. Business cycles for G7 and european countries. Journal of Business, 70:249-79, 1997.

\& Zhang, W. D. Further evidence on international business cycle and the ERM: Is there an european business cycle? Oxford Economic Papers, 51:120-32, 1999.

Bry, G. \& Boschan, C. Cyclical analysis of times series: selected procedures and computer programs. New York, National Bureau of Economic Research, 1971.

Burns, A. \& Mitchell, W. Measuring business cycles. New York, National Bureau of Economic Research, 1946.

Chauvet, M. An econometric characterization of business cycle dynamics with factor structure and regime switches. International Economic Review, 39(4):969-96, 1998.

- A monthly indicator of Brazilian GDP. Brazilian Review of Econometrics, 21(1), 2001.

\& Potter, S. M. Recent changes in the US business cycle. The Manchester School, 2001. Forthcoming.

\& Yu, C. International business cycles in the G-7 countries. University of California, Riverside, 2000. mimeog.

Contador, C. \& Haddad, C. Produto real, moeda e preços: a experiência brasileira no período de 1861-1970. Revista Brasileira de Estatística, 143(36):407-40, 1975.

Dickey, D. A. \& Fuller, W. A. Distribution of the estimators for autoregressive time series with a unit root. Journal of the American Statistical Society, 74:427-31, 1979.

Diebold, F. X. Rudebusch, G. D. Scoring the leading indicators. Journal of Business, 62(3):369-91, 1989.

Garcia, R. Asymptotic null distribution of the likelihood ratio test in Markov switching models. International Economic Review, 39(3):763-88, Aug. 1998.

Hamilton, J. A new approach to the economic analysis of nonstationary time series and the business sycle. Econometrica, 5\%:357-84, 1989. 
Hansen, B. E. The likelihood ratio test under non-standard conditions: testing the Markov trend model of GNP. In: Pesaran, M. H. \& Potter, S. (eds.). Nonlinear dynamics chaos and econometrics. John Wiley \& Sons, 1993. p. 5373.

Harding, D. \& Pagan, A. Knowing the cycle. Journal of Monetary Economics, 2001.

Haywood, E. The deviation cycle: a new index of the Australian business cycle, 950-1973. Australian Economic Review, 4:31-9, 1973.

Kim, C-J. \& Nelson, C. Has the US economy become more stable? A Bayesian approach based on a Markov switching model of the business cycle. Review of Economics and Statistics, 81(4):1-10, 1999.

Koop, G. \& Potter, S. M. Nonlinearity, structural breaks or outliers in economic time series? In: Barnett, William (ed.). Nonlinear econometric modeling in time series analysis. Cambridge, Cambridge University Press, 2000. p. $61-78$.

McConnell, M. \& Perez, G. Output fluctuations in the United States: what has changed since the early 1980s? American Economic Review, 90(5):1.464$76,2000$.

Mitchell, W. Business cycles: the problem and its setting. New York, National Bureau of Economic Research, 1927.

Neftci, S. Optimal prediction of cyclical downturns. Journal of Economic Dynamics and Control, 4:225-41, 1982.

Perron, P. The great crash, the oil price shock, and the unit root hypothesis. Econometrica, 5\%:1.361-401, 1989. 